\title{
Making a Digital Contour Map
}

\author{
Ilham Marsudi \\ Universitas Negeri Yogyakarta \\ Yogyakarta, Indonesia \\ ilham@uny.ac.id
}

\begin{abstract}
This research aims to create a digital contour map coordinates and elevation data obtained with Google Earth Pro, TCX Converter is used to convert the data into a file .xls tables and Spatial analyst Tool installed in ArcGIS used to continue to be a digital contour map. Done taking the coordinate points on most surfaces with Google Earth and saved as a file $\mathrm{Kml}$, further from $\mathrm{Kml}$ file is converted to coordinate data obtained latitude, longitude, and altitude in Excel .xls format. Proceed with the process up into a digital contour map with Spatial Analyst Tool installed in ArcGIS. Distribution of the high points were selected in Volcano Fragment Progo River, Rice fields around the river Progo, narrow area in the hamlet Ngajaran-BambanglipuroBantul, Region Adisucipto airport is taken three times, random pattern, a pattern of horizontal and vertical patterns. Digital contour map results will be closer to reality if the spread of the points used as inputs for digital maps patterned loose (not too tightly) regular distances between one another and proportional.
\end{abstract} UTM

Keywords-Digital contour maps, Latitude-Longitude-Altitude,

\section{INTRODUCTION}

In the implementation of development in various fields of civil engineering, for example, about the design of city planning, irrigation (agriculture), mining (mining plan), planning the manufacture of housing, planning for the port, geological mapping (inventory quarrying), construction planning, planning of roads and bridges on public works, all of which require preliminary information is their Topographical maps, one of which must exist beforehand is a contour map.

The technique of making a contour map two decades ago are still made by hand, while in the present and even bigger in the future, all work or civil engineering work plans are supposed to use certain software to produce digital contour map. It may be said digital contour maps must bring there before something other work resumed. Contour maps that are digital, which means that the map contains a collection of figures coordinates (easing, northing), longitude-latitude. This triggers assortment of software that can be used for various purposes of work based on figures coordinates. The current software is popular is paid ArcGIS (www.esri.com), artificial Environment System Research International, headquartered in New York Street, California, USA and QGIS (Quantum GIS), made in a non-profit organization is free to use, unpaid (free), as well as Google Earth, as the software is web-based manager coordinates. The main requirement to be made a contour map is the presence of multiple data points that already have the coordinates (Easting, Northing) and altitude (elevation) than on those points. Work to obtain the data necessary field work is time-consuming, while the work required to always quick time, so as to obtain data are now also not always directly from the field (terrestrial survey), but through satellite imagery has been widely circulated. Some of the satellite images can be ordered easily, but there are also free of charge as from Google-earth image.

From the above situation, this study aims to manufacture digital contour maps with Google Earth Pro, TCX Converter, Microsoft Excel, coordinates and elevation data storage in a table format, Spatial Analyst Tool which is an additional program that is in ArcGIS. The software program, among others, with ArcGIS, Spatial extension Analyst Tool, TCX Converter, and Google Earth Pro as a tool to obtain data on the high points on the earth's surface.

\section{THE FOUNDATION OF THEORY}

\section{A. Analog contour map}

Analog contour map, a map that are static (fixed scale), generally printed on a piece of paper, the paper can also field replaceable monitor, contain curved lines, and each line is a height (elevation) of the same. Thus not impossible contour lines intersect, since there may be a common point has two heights. Contour lines were obtained by connecting some dots are positioned at specific coordinates and altitude the same particular. In the contour maps, the coordinates can be local, meaning that only applies in a contour map of the course, can't be associated with contour maps of the others. There is also a have coordinate that have been geo referenced, such as the coordinates that have had UTM coordinate system (Universal Transverse Mercator) used in Indonesia, or may be of longitude-latitude coordinate system (Geographic Coordinate). In the civil engineering work large areas such as irrigation work coordinate system UTM used, whereas for the work planning of houses, bridges, football stadium that its scope is small, just use local coordinates. Some examples of the form contour maps:

- Peak, hilly contour lines are marked with contour lines were shut down, (closed loop) with a reduced diameter of the loop, but figures ascending height, shown in Figure 1.
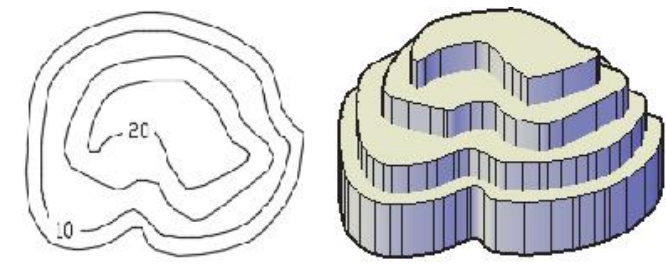

Fig. 1 .

Contour hills 2D and 3D 
- Depression, the inverse of the peak (hills), the loop diameter is also smaller, and with smaller numbers, so getting into the shrinking elevation. Loop is under the least recognizable as hachures, shown in Figure 2.
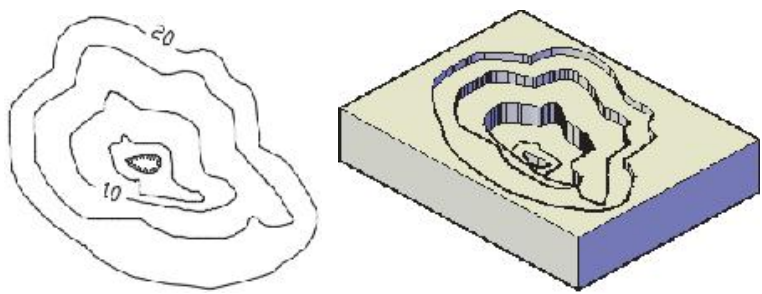

Fig. 2.

Contour depression 2D and 3D

- Saddle, ascending contour (like a hill) but one side is almost perpendicular cliff between the very top to the very bottom (slope approaching $90^{\circ}$ ), so that the contour lines almost coincide, are shown in Figure 3.

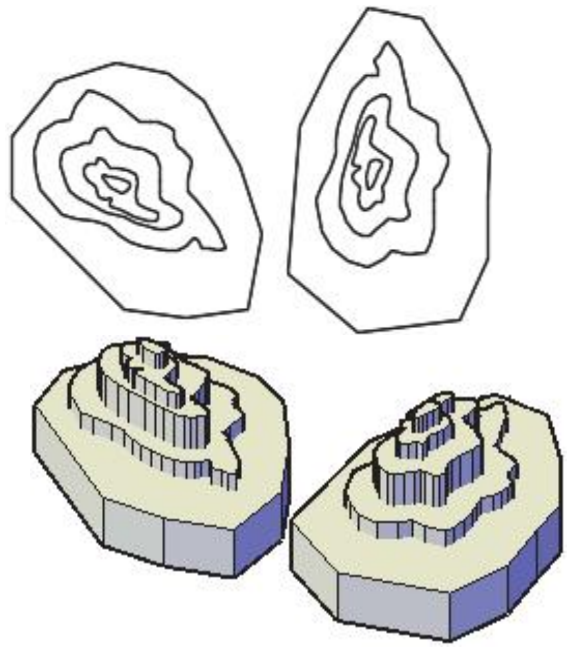

Fig. 3. Contour 2D and 3D cliff

- Streams, contour lines are almost parallel to each other, so that from above as being open $\mathrm{V}$ shape from the bottom V-shaped closed contour described the river with cliffs that flank on the left and right, punctuated by drawings 4 .
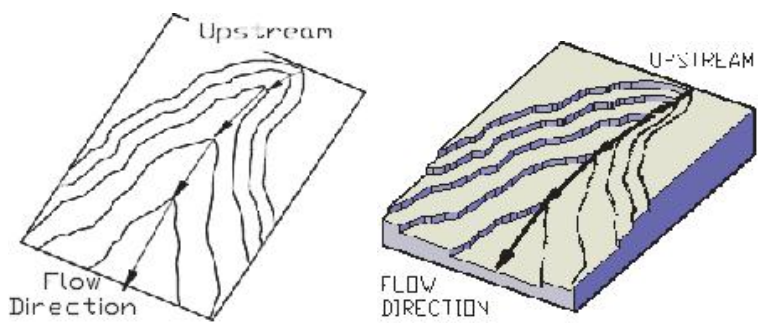

Fig. 4.

Contour V shape state 2D and 3D

- Ridge or a hill or mountain, contour lines on some hills (hills), so that on the left image 5a formed an inverted $\mathrm{V}(=\Lambda)$, followed that in the middle (which is a hill) to form the letter $U$ and $\Lambda$ again, so that in the mountains the hilly be formed order of the letter is $\Lambda \mathrm{U} \Lambda \mathrm{U} \Lambda \mathrm{U} \Lambda$, punctuated by drawings 5 .
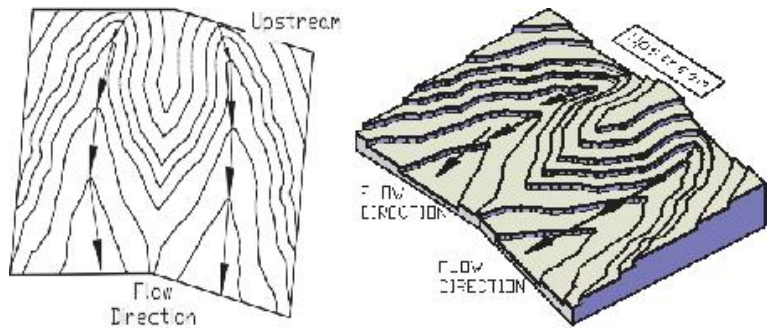

Fig. 5.

Contour lines $\Lambda \mathrm{U} \Lambda$ state form of $2 \mathrm{D}$ and $3 \mathrm{D}$

- Slope verses space, contour on a hill, there is a high side slope (step slope), are shown in Figure 6 the left side, and the other side with a low slope (milder slope), are shown in Figure 6 the right.

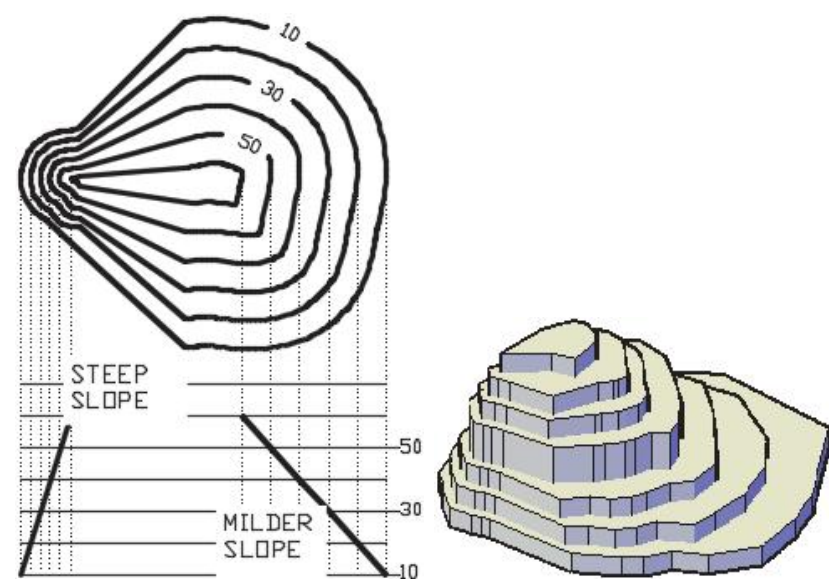

Fig. 6. Contour steep and milder slope 2D and 3D

From the description of the contour line above, one can be made a few categories of properties attached to the contour lines, among others:

- Two contour lines can't intersect, since it is impossible one point had two the same height.

- Shaped closed curve.

- No branches.

- Indented upstream if the rivers.

- Indented toward a downhill road when passing through the road surface.

- Not envisaged if passing through the building.

- Tight contour lines show the state of the steep ground.

- Contour lines that rarely shows the state of the sloping surface.

Presentation of the contour interval depends on the scale of the map is presented, if the flat contour interval depends on the scale of the map is presented, if the flat contour interval is $1 / 1000$ times the scale of the map, if hilly $1 / 500$ times the scale of the map and if mountainous 1/200 times the scale of the map. 
Presentation index contour lines on a flat area of any difference of three contour lines, on a hilly area every four contour lines, while in the mountainous region of each increment 5 contour lines. Contour lines around the lower elevation contour lines higher elevation. The series of contour lines indicating a U-shaped ridge, while a series of contour lines that form the letter $\Lambda$ denotes a valley / ravine.

\section{B. The digital contour map}

In contrast to map analog, maps (contours) digital is a display on the monitor screen coordinate points that shaped nodes and vertex-vertex, coordinate system Geographic or projections (for example UTM used Indonesia) of the basespatial data that is stored and managed by specific software (specialized software processing spatial data) on a computer (Personal computer, Laptop, Tablet, or Smartphone), can also be said that a contour map digital is a softcopy of spatial data specific stored on the computer, while the hardcopy is the print if softcopy are printed on a sheet of paper, or when the softcopy photographed on the monitor screen (print screen) it is already a digital photograph of a soft copy digital map

The digital map is very dynamic, especially on a scale map can be arranged at the user, enlarged or reduced, can be enlarged to a scale of 1: 1 with no experience the quality of the image changes, due to the nature of vector data, not raster. For the provision of illustration contour maps digital must open an existing computer program processing spatial data, such as ArcGIS (artificial ESRI International, MapInfo (MapInfo Corporation), QGIS (artificial-profit organization) and there are others, and that is no less important is the absence of data spatial coordinates. However, to give just a snapshot illustrations 7. (print screen) of digital contour map, the hardware Laptop, ArcGIS 10.2 software, spatial data stored in D: \18-oct-2016 \Data17oct16 \Bandara17 \bandara1 । bandara.mdx.

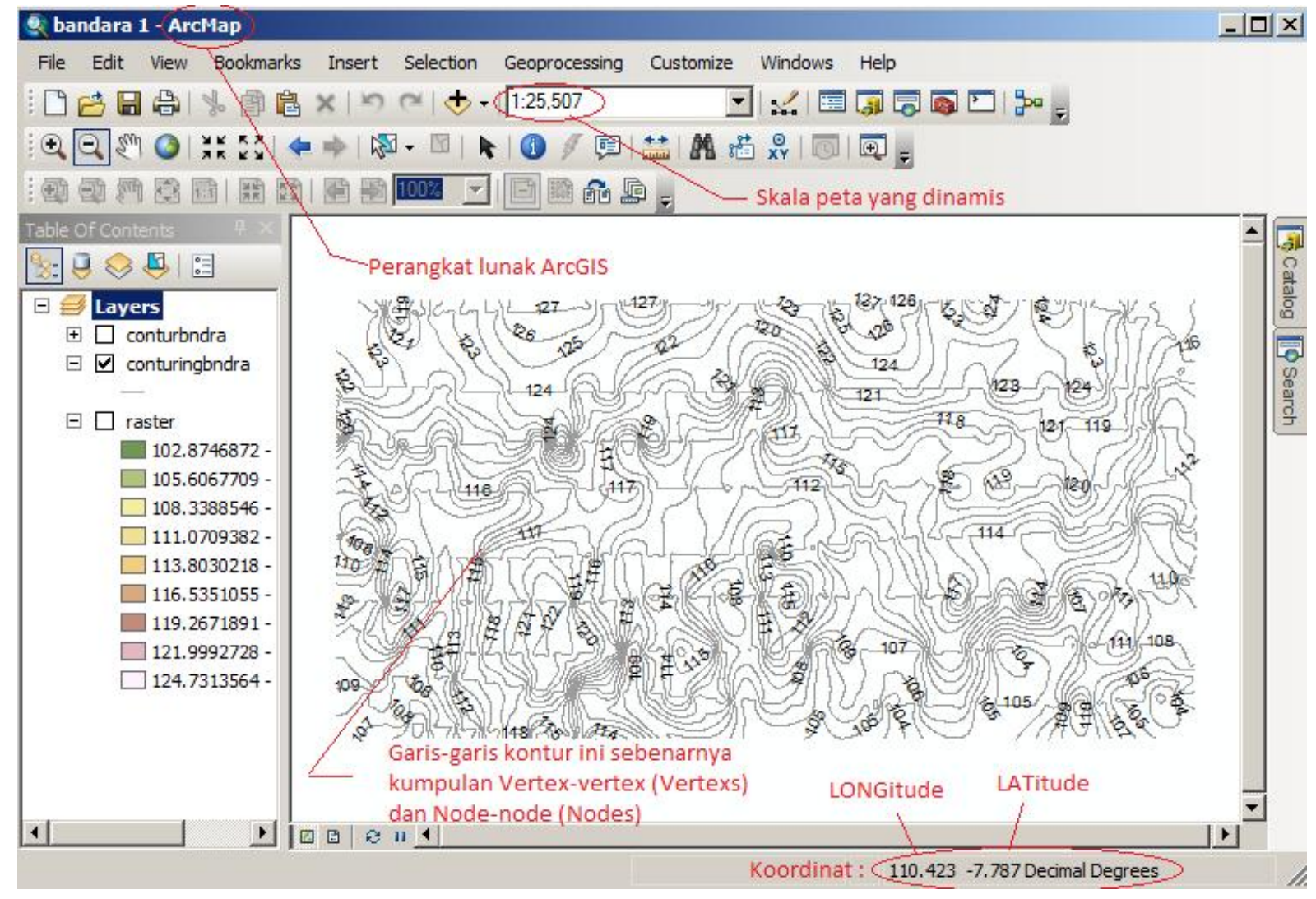

Fig. 7. Print screen of the digital contour map

\section{THE PROCESS OF MAKING DIGITAL CONTOUR MAP}

\section{A. The digital elevation data}

Data points heights obtained by using Google Earth Pro, by selecting (click) with the mouse to the area you want to create contour maps, then stored as a KML file.

\section{B. Conversion of data}

From the data in KML format conversion to be a tabular format .xls with TCX Converter program. 


\section{The process of becoming a contour map}

From the data tables xls format, processed Analyst Spatial Tool embedded in ArcGIS program into a digital contour map.

\section{DISCUSSION}

Contour lines are generated from all experiments there that violates the rules that intersect or overlap one another.

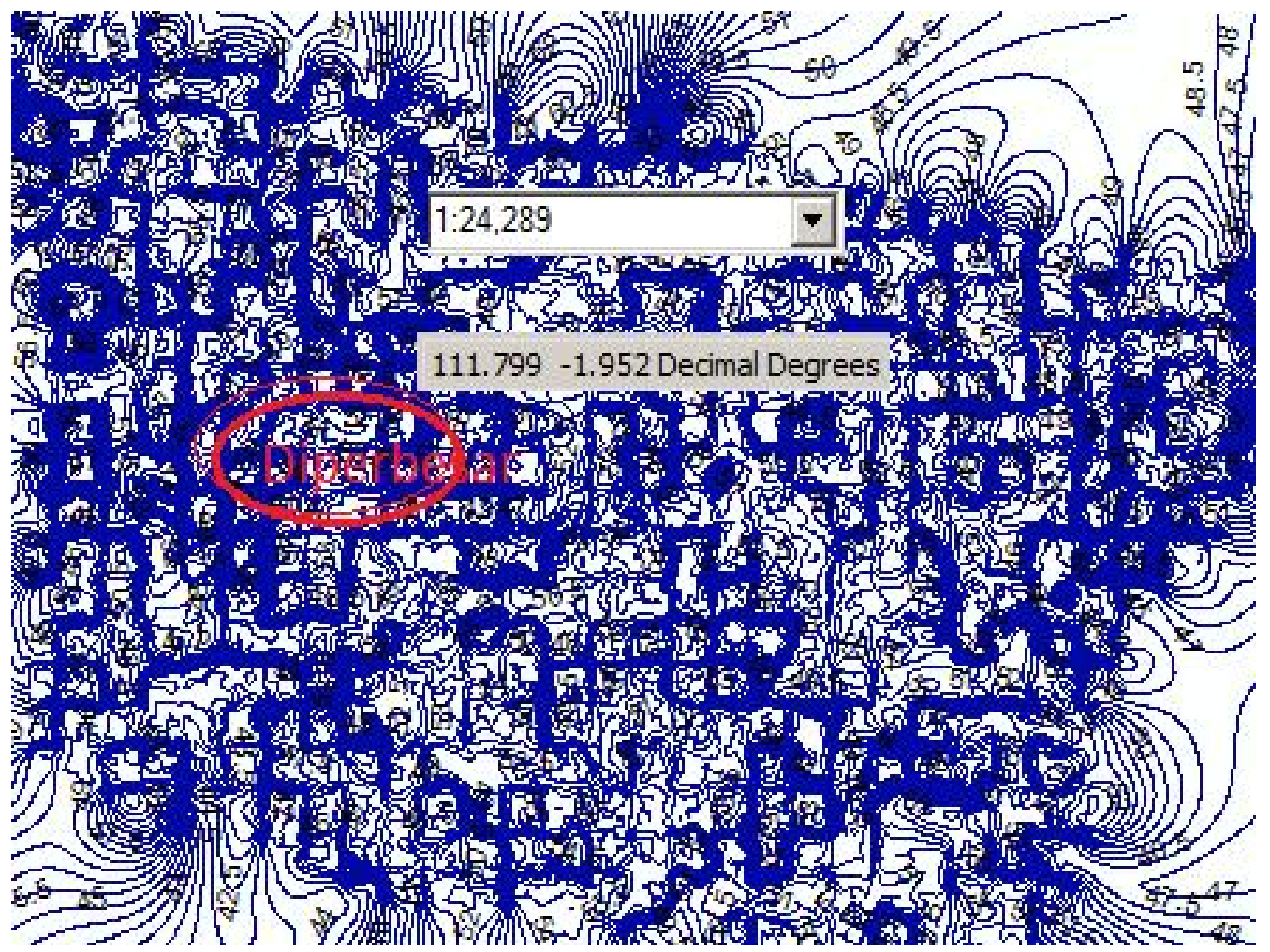

(a)

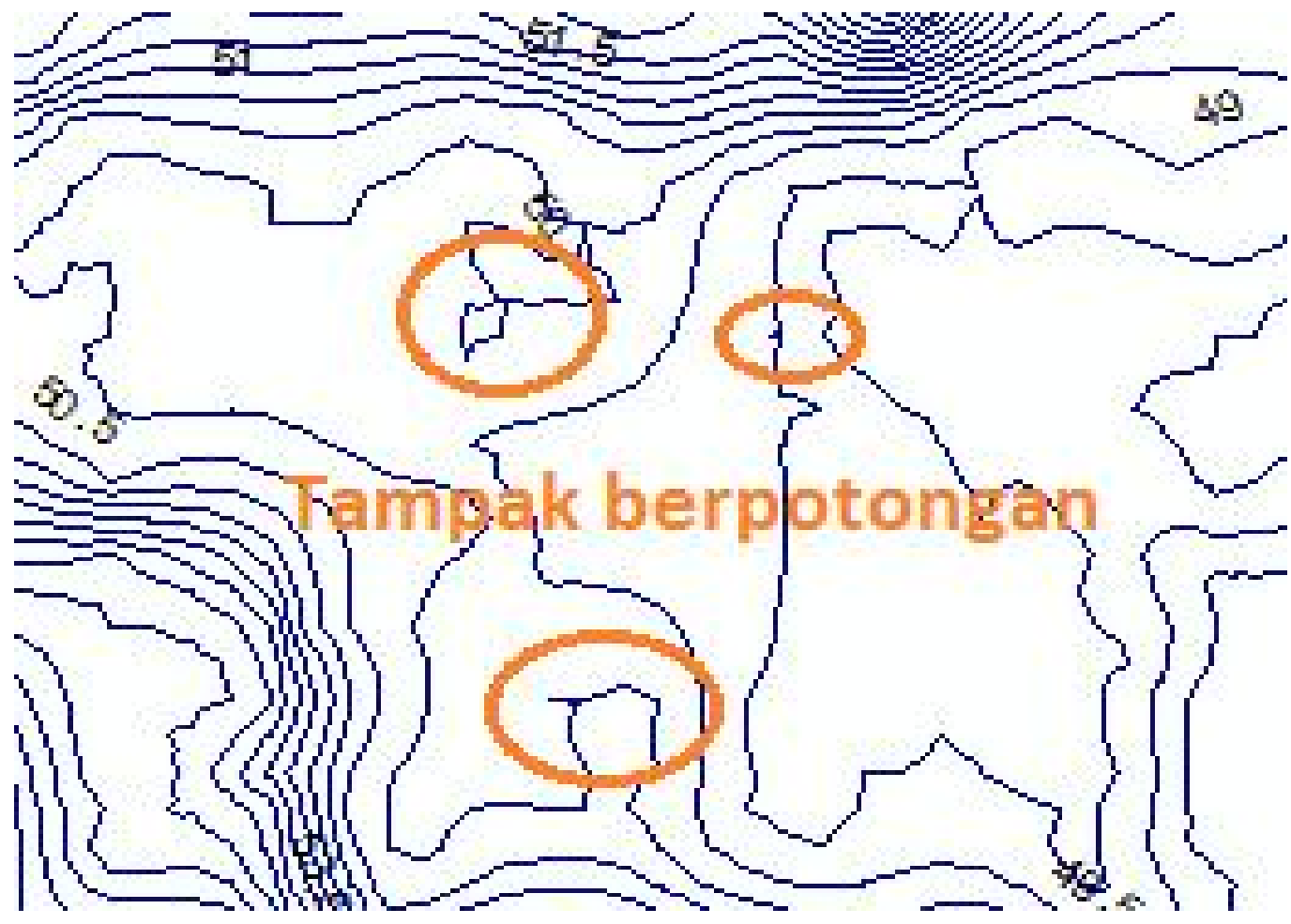

(b) 


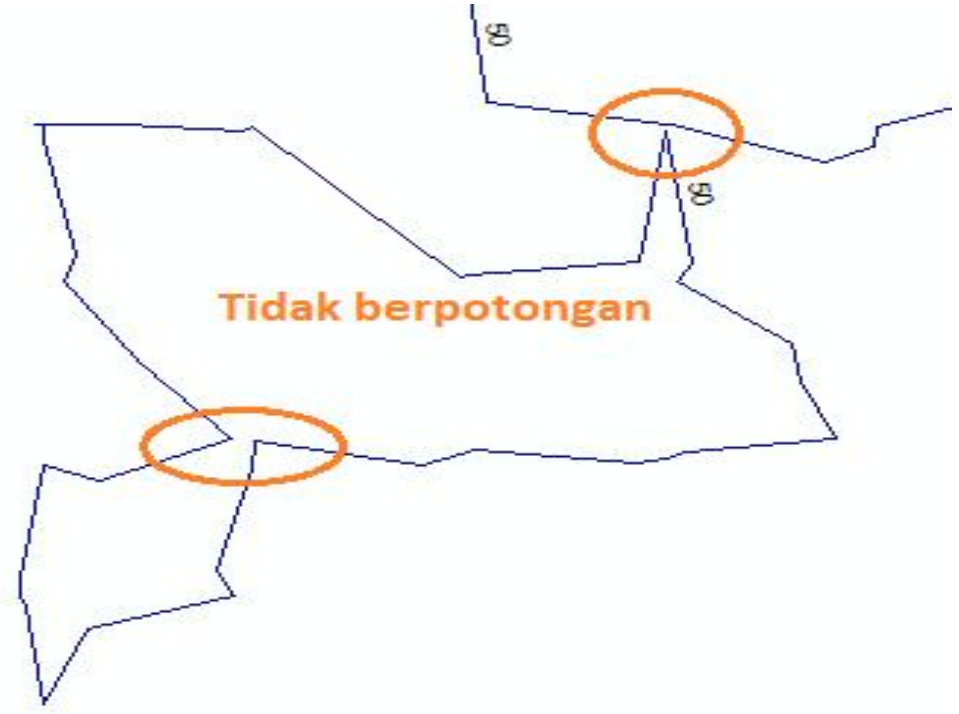

(c)

Fig. 8. Contour lines appear to intersect (a), The first magnification (b), The second magnification (c)

In the figure 8a. Meeting many contour lines, but nothing that intersect or intersect, magnification shown in Figure 8b and $8 \mathrm{c}$. But the contour lines to be ugly because the line should contour curved-arch and does not form an angle, as shown in Figure 8c. Distribution points that the meeting will form a lot of contour lines that form polygons closed adjacent to the same height, it applies to a wide area (for example in the area of Central Kalimantan) and narrow, in Hamlet Ngajaran-BantulYogyakarta, is shown in 9a and $9 \mathrm{~b}$ picture image.

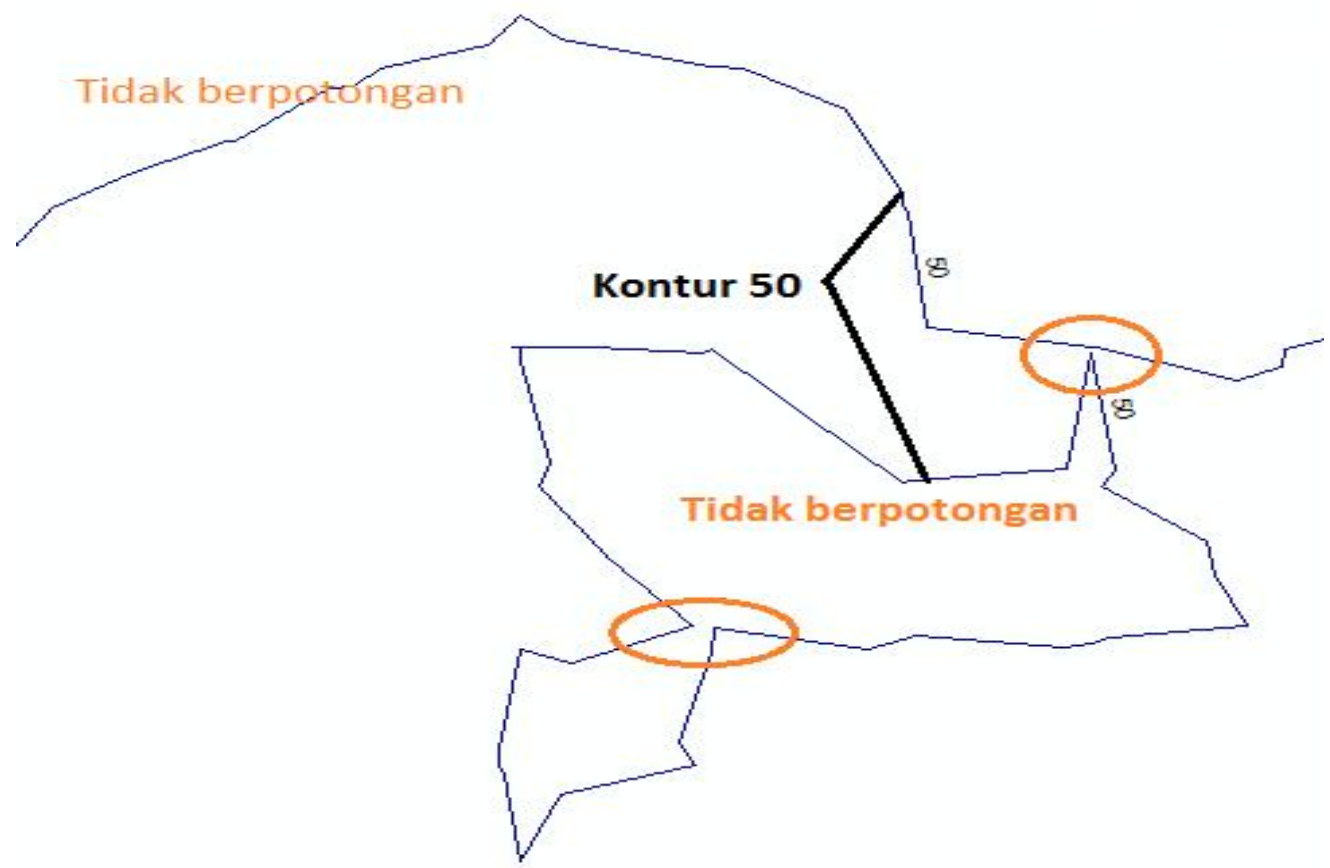

(a) 


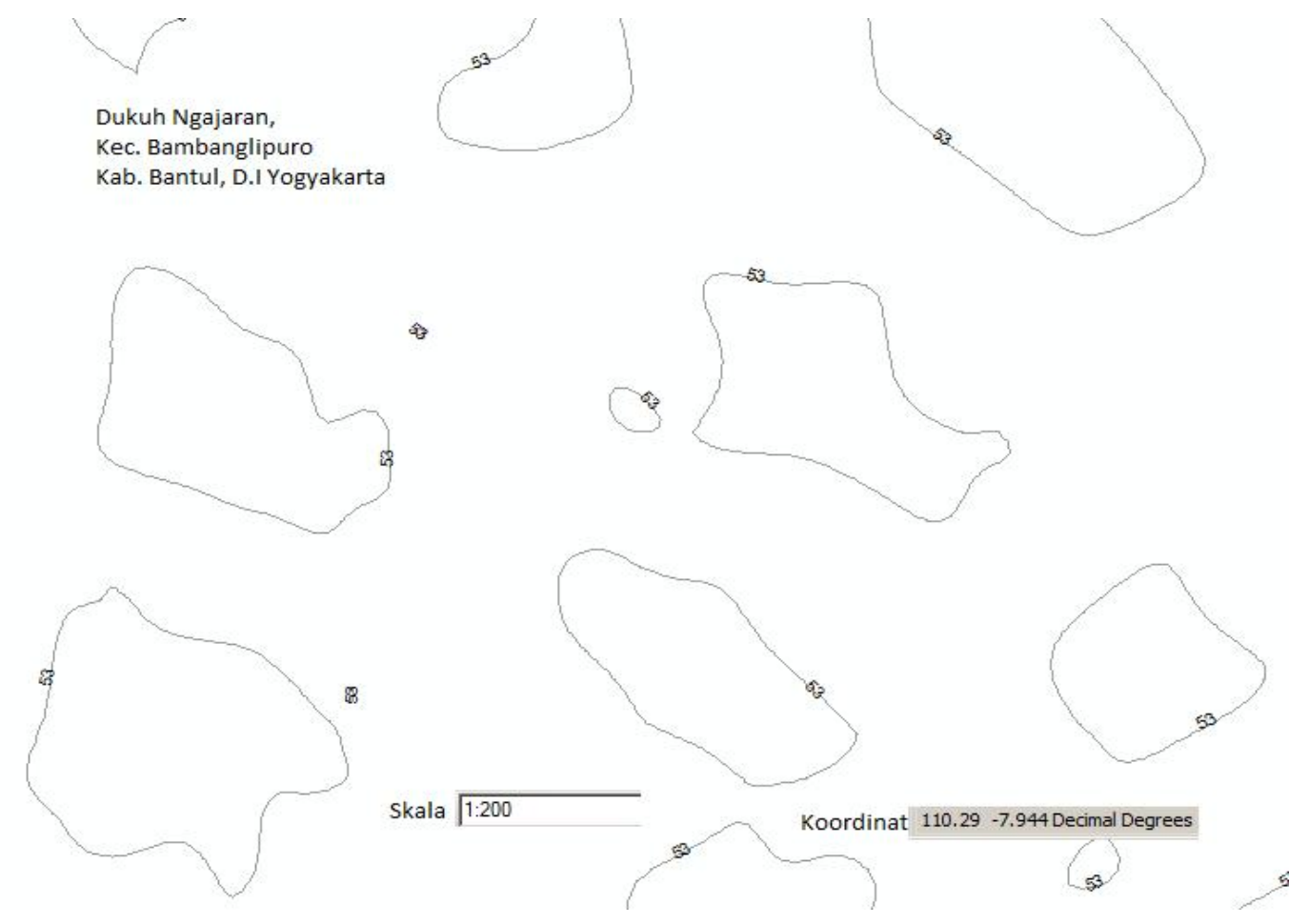

Fig. 9. Contour line 50 more than one polygon in Central Kalimantan (a), Contour lines 53 there are more than 9 same (b)

Although the distance between the drawing point coordinates are tenuous, but the result of a line contour has a roundness irregular and have the same height (in this case 53), this means that if the state of the ground is relatively flat and the area is quite narrow do not need the distance between the point of being equal, it means distribution point aka taken also do not have to like grid or have a meeting or to be tenuous, but proportionally, for example, to a flat area, just one, as there are areas such instance $5.5 \mathrm{f}$ picture, taken enough points $1,2,3,4$, 5,6 , and 7 , the dots are red not need to be taken, drawing 5.6 however be difficult to know the state of the ground surface profile when done through satellites such as those used Google Earth.

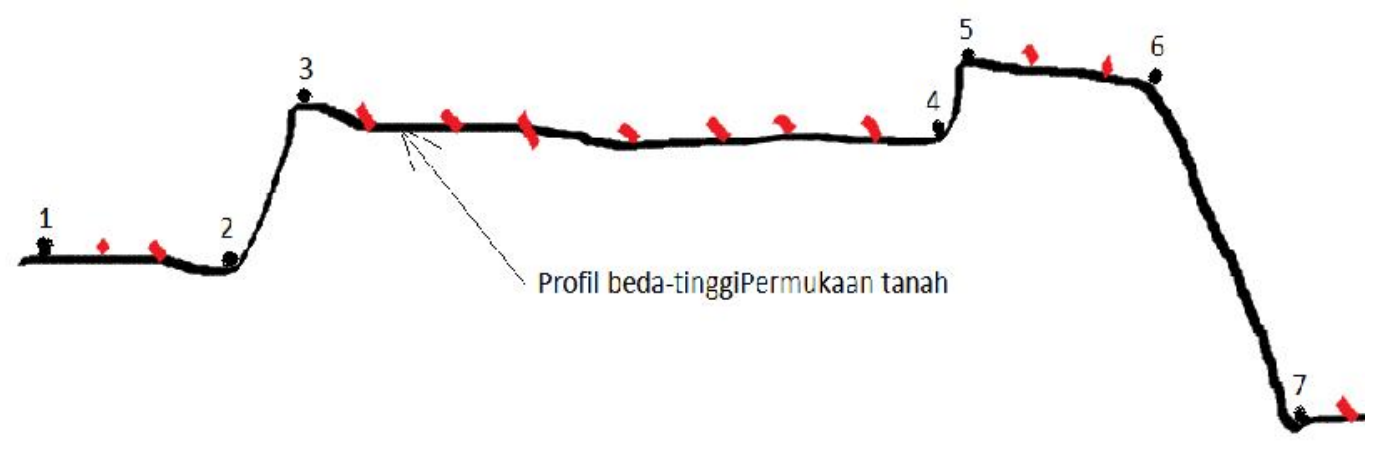

Fig. 10. The points that need and do not need to be taken

\section{CONCLUSION}

1. Contour lines that exist on a digital map nothing that violates the rules of the contour lines, one of which is not supposed to happen or cutting contour lines intersect with each other.
2. Distribution points (latitude, longitude, and altitude) are tight and irregular if used in large area and small area is always the same result, which produces a lot of contour lines that form a closed adjacent polygons that have the same height.

3. Distribution points (latitude, longitude, and altitude) were tenuous and more regular contour lines generated is 
proportional, meaning will be the same result between created by the program and by humans.

\section{SUGGESTIONS}

1. It should be attempted retrieval of data points elevation (Digital Elevation Model-DEM) using other means, for example satellite image used has a high resolution, so that the state of the Earth's surface more clearly.

2. It is possible to make a contour map directly in Google Earth without any other additional software.

\section{REFERENCES}

[1] CIVL 1101 - Making Contours with ArcGIS, http://www.ce.memphis.edu/1101/GIS/arcmap_intro/ArcMap_contour.h tml
[2] Contour Maps and Their Uses, http://theconstructor.org/surveying/contour-maps-uses/6441/

[3] Contouring by Hand, https://www.e-education.psu.edu/geog482spring2/c7p6.html

[4] Give Introduction of Contouring, http://www.engineeringcivil.com/theory/surveying

[5] How to Create a Contour Map Effect in Illustrator, http://blog.spoongraphics.co.uk/tutorials/create-contour-map-effectillustrator

[6] Uses of Contour maps and Characteristics of Contours, http://www.civilengineeringterms.com/surveying-levelling/termsrelated-to-contouring-objects-of-contouring-uses-of-contour-mapscharacteristics-of-contours-methods-of-contouring/

[7] What are the Uses of Contours, http://www.engineeringcivil.com/what-are-the-uses-of-contours.html 